\title{
SEVERIDADE DE Cercospora sojina HARA EM SOJA TRANSGÊNICA BRS VALIOSA RR NO ESTADO DO MARANHÃO, SOB DIFERENTES DOSAGENS DE AGROSILÍCIO
}

\author{
Thatyane Pereira de Sousaㄹ; Ivaneide Oliveira Nascimento²; Claudio Belmino Maia²; Patrícia \\ Sumara Moreira Fernandesi'; Joacir Moarais'; Suzana Silva Gonçalves. \\ ${ }^{1}$ Discente do Curso de Agronomia da Universidade Estadual do Maranhão, thatyane_@ @otmail.com \\ 2 Pesquisador(a) do Departamento de Agronomia da Universidade Estadual do Maranhão
}

RESUMO: A soja Glycine $\max$ (L.) Merrill é afetada no campo por várias doenças fúngicas, algumas bacterianas, além de viroses e nematóides. A cercosporiose ou mancha olho de rã, provocada pelo fungo Cercospora sojina Hara, causa perdas no cultivo da soja. Atualmente, há evidências de 25 raças do patógeno no Brasil e novas raças podem ocorrer. O objetivo deste trabalho foi determinar o nível de incidência de $C$. sojina Hara na cultivar de soja transgênica BRS Valiosa RR no Maranhão. O Ensaio foi instalado na área do Sindicato Rural de Imperatriz, localizado na BR $010 \mathrm{Km}, 24$. O Delineamento foi disposto em blocos ao acaso com parcelas subdivididas com 4 repetições, Foram utilizados 5 tratamentos com 5 doses diferentes de agrosilício. A avaliação do experimento foi realizada após 60 dias após o plantio e realizado por meio de leituras visuais, através de uma escala diagramática para a quantificação das enfermidades de final de ciclo para a cultura da soja. Foram encontrados sintomas de mancha olho de rã em apenas 9 parcelas, a maioria das plantas infectadas apresentaram área foliar com manchas de 1 a $5 \%$ e 6 a 15\%, Os tratamentos com 0 e 8 t/ha de agrosilício apresentaram maior incidência de cercosporiose, dosagens 1,2 e 4 t/ha de agrosilício não diferiram em relação à incidência da doença.

PALAVRAS -CHAVE: cercosporiose, cultura, incidência.

\section{SEVERITY OF Cercospora sojina HARA ON SOYBEAN BRS RR VALUABLE AS MARANHÃO UNDER DIFFERENT STRENGTHS OF AGROSILÍCIO}

\begin{abstract}
Soybean Glycine $\max (\mathrm{L}$.$) Merrill is affected by the field wide range of fungal$ diseases, some bacteria, and viruses and nematodes. Cercospora leaf spot, or stain-frog-eye, caused by the fungus Cercospora sojina Hara, causes severe losses in soybean cultivation. Currently, there is evidence of 25 races of the pathogen in Brazil and new races may occur. Goal from work was to determine the level of incidence of $C$. sojina Hara in transgenic soybean BRS Valuable RR Maranhão. The test was installedin the area of the Rural Union of Empress, located in BR $010 \mathrm{Km} \mathrm{24}$. The experiment was arranged in blocks with split plot design with four replications, were used five treatments with five different doses of agrosilício. The evaluation of the experiment was carried out 60 days after planting and is performed by visual readings, using a diagrammatic key to the quantification of disease to late season soybean crop. Symptoms were found to stain eye frog in only 9 parcels, most of the infected plants showed leaf area with patches of 1 to $5 \%$ and $6-15 \%$, treatments with 0 and $8 \mathrm{t} /$ ha agrosilício a higher incidence of gray leaf spot, doses 1, 2 and $4 \mathrm{t} /$ ha agrosilício not differ in disease incidence.
\end{abstract}

KEY- WORDS: cercosporiose, culture, incidence. 
A soja Glycine max (L.) Merrill é afetada no campo por várias doenças fúngicas, algumas bacterianas, além de viroses e nematóides (HENNING, 1996).

Estudos sobre a importância das doenças da soja têm demonstrado que elas são responsáveis pela redução em média de 15 a $20 \%$ de rendimento potencial da cultura, além de causar manchas que depreciam o valor comercial das sementes (MENTEN, 1991).

Os patógenos Colletotrihcum dematium var. truncata (Schw.) Von Arx, Phomopsis sojae Lehman, Cercospora kikuchii (Matsu. e Tomoy) Gardner, Cercospora sojina Hara e Septoria glycines Hemmi, são os mais freqüentemente disseminados através das sementes. A prevalência e a severidade das doenças depende da presença de patógeno virulento, da suscetibilidade da cultivar plantada e das condições ambientais favoráveis (EMBRAPA, 2003).

A cercosporiose, ou mancha olho de rã, provocada pelo fungo Cercospora sojina Hara, causa grandes perdas no cultivo da soja. Atualmente, há evidências de 25 raças do patógeno no Brasil e novas raças podem ocorrer (YORINORI e KLINGELFUSS, 2000).

A mancha olho de rã está sob controle no Brasil devido ao uso de cultivares resistentes, mas foi a primeira doença epidêmica da cultura da soja no país, responsável por grandes perdas até o final da década de 80 (DEL PONTE, 2011).

O patógeno causa lesões em folhas, hastes, vagens e sementes. Os sintomas primários são pontuações de até $5 \mathrm{~mm}$ de diâmetro, com um centro castanho-claro e bordas amarronzadas na face adaxial das folhas (DEL PONTE, 2011).

A utilização de cultivares resistentes à doença tornou esporádica a presença do patógeno em lotes comerciais de semente (HENNING, 2005). O objetivo deste trabalho foi determinar o nível de incidência de Cercospora sojina Hara na cultivar de soja transgênica BRS Valiosa RR no Maranhão.

$\mathrm{O}$ ensaio foi instalado na área do Sindicato Rural de Imperatriz - SINRURAL, no Parque de Exposição localizado na BR 010 $\mathrm{Km}, 24$.

O delineamento foi disposto em blocos ao acaso com parcelas subdivididas com 4 repetições, cada parcela com $12 \mathrm{~m}$ de comprimento e $6 \mathrm{~m}$ de largura contendo 20 linhas com espaçamento de 0,45 $\mathrm{m}$ entre linhas, sendo 10 linhas com a semente de soja BRS Valiosa RR e 10 linhas com a variedade BRS 7860 RR sendo a área de cada parcela 72 $\mathrm{m}^{2}$ e cada bloco $384 \mathrm{~m}^{2}$, área total de 1728 $\mathrm{m}^{2}$. Foram utilizados 5 tratamentos com 5 doses diferentes de agrosilício. (0, 1, 2, 4, 8 t/ha de Agrosilício). 
A avaliação do experimento foi realizada 60 dias após o plantio da soja, por meio de leituras visuais, através de uma escala diagramática para a quantificação das enfermidades de final de ciclo para a cultura da soja (MARTINS, 2004), variando de 1 a 6, sendo 1 para plantas sem manchas na área foliar, 2 para folhas com manchas na área foliar de 1 a 5\%, 3 para 6 a 15\%, 4 para 16 a $35 \%, 5$ para 36 a 50\%, 6 para folhas com manchas na área foliar superior a 50\% da área total das folha.
A análise visual realizada na área de ocorrência de Mancha Olho de rã, que tem como agente causal o fungo Cercospora sojina, possibilitou identificar a incidência de da doença na área.

O experimento era composto por 20 parcelas, foram encontrados sintomas de mancha olho de rã em apenas 9 parcelas. Conforme mostra a tabela.

Tabela 1. Ocorrência de Mancha Olho-de-rã coma atribuição de nota de acordo com a Escala Diagramática.

\begin{tabular}{l|l}
\hline Tratamento & $\begin{array}{l}\text { *Notas atribuídas às plantas } \\
\text { infectadas }\end{array}$ \\
\hline Bloco I (0 t/ha de agrosilício) & 3 \\
Bloco I (1 t/ha de agrosilício) & 3 \\
Bloco I (2 t/ha de agrosilício) & 1 \\
Bloco I (4 t/ha de agrosilício) & 2 \\
Bloco I (8 t/ha de agrosilício) & 2 \\
Bloco II (0 t/ha de agrosilício) & 2 \\
Bloco II(1 t/ha de agrosilício) & 1 \\
Bloco II(2 t/ha de agrosilício) & 1 \\
Bloco II (4 t/ha de agrosilício) & 1 \\
Bloco II (8 t/ha de agrosilício) & 2 \\
Bloco III (0 t/ha de agrosilício) & 1 \\
Bloco III (1 t/ha de agrosilício) & 1 \\
Bloco III (2 t/ha de agrosilício) & 2 \\
Bloco III (4 t/ha de agrosilício) & 1 \\
Bloco III (8 t/ha de agrosilício) & 1 \\
Bloco IV (0 t/ha de agrosilício) & 3 \\
Bloco IV (1 t/ha de agrosilício) & 1 \\
Bloco IV (2 t/ha de agrosilício) & 1 \\
Bloco IV (4 t/ha de agrosilício) & 1 \\
Bloco IV (8 t/ha de agrosilício) & 3 \\
\hline
\end{tabular}

*Nota 1: Folhas sem manchas; Nota 2: Folhas com manchas na área foliar de 1 a 5\%; Nota3: Folhas com manchas na área foliar de 6 a $15 \%$. 
Como pode ser observado a maioria das amostras de plantas infectadas apresentaram nota 2 de acordo com a escala de notas, onde tinham a área foliar com manchas de 1 a 5\%.

Apenas em 4 parcelas foram encontradas folhas apresentando manchas entre 6 a $15 \%$ de sintomas da doença.

Os tratamentos de 0 t/ha e $8 \mathrm{t} / \mathrm{ha}$ de agrosilício foram os que mais apresentaram ocorrência de mancha olho-de-rã, com incidência de variando entre as notas 2 e 3. Já os tratamentos com 1, 2 e 4 t/há de agrosilício não diferiram em relação à incidência da doença.

Com base no Experimento realizado a dosagem indicada para redução da incidência de cercosporiose seria de 1 t/há, tendo em vista que as dosagens de 2 e 4 t/ha tem o mesmo efeito.

O trabalho realizado torna-se relevante para a cultura da soja pois até o momento pode ser considerado um dos pioneiros envolvendo aplicação de agrosilício, fazendose necessário o aprofundamento de pesquisas em torno do tema para conclusões mais apuradas.

Os sintomas da mancha olho de rã eram visualizados basicamente nas folhas e estão de acordo com a definição de HENNING (2005) que caracteriza o sintoma mais típico da doença como sendo a presença de lesões castanho-cinza claro com bordas avermelhadas, as quais aparecem próximo a fase de floração.

Os sintomas encontrados nas folhas de soja em campo corresponderam as notas 2 e 3 da Escala Diagramática de acordo com análise visual;

Os tratamentos com 0 e 8 t/ha de agrosilício apresentaram maior incidência de cercosporiose;

As dosagens 1, 2 e 4 t/ha de agrosilício não diferiram em relação à incidência da doença.

\section{REFERÊNCIAS}

DEL PONTE, E.M. (Ed.) Fitopatologia.net: herbário virtual. Departamento de Fitossanidade/Agronomia/UFRGS. Disponíve 1 na Internet: http://www.ufrgs.br/agronomia/fitossan/ herbariovirtual. Acesso em: 08 junho 2011 YORINORI, J.T.; KLINGELFUSS, L.H. Novas raças de Cercospora sojina em soja. Fitopatologia Brasileira, v.24, p.509-512, 2000.

MENTEN, J.O.M. Prejuízos causados por patógenos associados às sementes. In: SEMANA DE AVALIAÇÃO EM PATOLOGIA DE SEMENTES, 2., Piracicaba, 1991. Anais... Piracicaba: ESALQ, 1991. p.115-136. 
HENNING, A.A. Patologia de Sementes:

Noções gerais. Londrina: EMBRAPA Soja, 2005. 52p.
MARTINS, M.C.; GUERZONI, R.A. CÂMARA, G.M.S. et al. Fitopatologia Brasileira v.29, n.2, 2004. 179-184. 